\title{
Social Marketing on Dengue Hemorrhagic Fever and Tuberculosis Prevention and Control Program in Pati, Central Java, Indonesia
}

\author{
Endang Sutisna Sulaeman ${ }^{1}$, Bhisma Murti ${ }^{1} \&$ Waryana $^{2}$ \\ ${ }^{1}$ Masters Program in Public Health, Sebelas Maret University, Indonesia \\ ${ }^{2}$ Department of Nutrition, School of Health Polytechnics, Yogyakarta, Indonesia \\ Correspondence: Endang Sutisna Sulaeman, Master Program in Public Health, Sebelas Maret University, \\ Indonesia. Tel: 62-817-774-236. E-mail: sutisnaend_dr@yahoo.com
}

\author{
Received: January 19, 2018 Accepted: February 5, 2018 Online Published: March 15, 2018 \\ doi:10.5539/gjhs.v10n4p100 \\ URL: https://doi.org/10.5539/gjhs.v10n4p100
}

\begin{abstract}
Indonesia has the highest number of dengue fever cases in Southeast Asia and the second highest TB cases in the world. Both diseases are related to behavior. Social marketing focuses on changes in health behaviors. This study aimed to apply social marketing on dengue mosquito vector control and TB case finding and to analyze the effect of social marketing training on the knowledge and skills of community health workers (CHWs). A mixed method design was conducted in Pati, Central Java, Indonesia. First, a case study was conducted using field observation, in-depth interviews, focus group discussions (FGD), and document review. In-depth interviews and FGD were conducted on 55 participants including 40 community leaders and 15 CHWs. Data were analyzed using content analysis. Second, intervention study was conducted on social marketing training of $30 \mathrm{CHWs}$. The independent variable was social marketing training. The dependent variables were knowledge and skill of dengue mosquito vector control and TB case finding. The effect of training was analyzed by paired t test. The results showed that knowledge $(\mathrm{p}<0.001)$ and skill $(\mathrm{p}<0.001)$ in dengue mosquito vector control and TB case finding increased significantly after training. Qualitative assessment showed that CHWs were more able to identify health problems in the community and to perform TB case finding and dengue mosquito breeding place eradication. After training they also became more knowledgeable in applying social marketing approach to address the health problem. In conclusion, social marketing strategy can be used to address community health problem.
\end{abstract}

Keywords: social marketing, vector control, case finding, dengue, TB, community health workers

\section{Introduction}

In Indonesia, the DHF and TB patients tend to increase in its number and to spread more widely. World Health Organization (2015) reported Indonesia as the state with highest DHF case in South East Asia. In 2015, the number of DHF patients reported increased by 129.650 cases with 1.071 deaths. Incidence Rate (IR is the number of new cases of a disease occurring in an area over a period of time) of 39.80 in 2014 to 129.650 with mortality rate of 1.071 people in 2015 (IR $=50.75$ per 100,000 populations, and Case Fatality Rate (CFR is the proportion of people dying of dengue disease among people suffering from the disease) $0.83 \%$, compared to 2014 with cases of 100.347 and IR 39.80 (Ministry of Health Republic of Indonesia 2016). DHF cases increase and diffuse due to behavioral factor and inadequate community participation in eradicating mosquito nests and the increased population number and mobility resulting in wider and easier distribution of DHF virus (Ministry of Health Republic of Indonesia, 2010).

Meanwhile, Indonesia is the state with the second largest number of TB patients following India, $10 \%$ of patients in the world. TB prevalence rate in Indonesia is 647/100.000 populations, increasing from 272/ 100.000 populations in previous year, IR is 399/100.000 populations increasing from 183/100.000 populations in 2013, and the mortality rate is $41 / 100.000$ populations increasing from $25 / 100.000$ in 2013. Meanwhile, Case Notification Rate (CNR is the number of all TB cases were treated and reported in every 100,000 of the population in a particular area) of new pulmonary TB cases is 74/100.000 populations in 2015 , decreasing from $77 / 100.000$ populations in 2014. Meanwhile, CNR of total TB cases is 130/100.000 populations in 2015 increasing from $129 / 100.000$ populations in 2014. Success Rate (SR is percentage of TB cases successfully treated among TB cases notified to the national health authorities during a specified period) is $85.5 \%$ in 2015 (data per June 2016). WHO's standard successful treatment rate is 85\% (WHO report 2015-2016). One attempt of changing health 
behavior is to conduct social marketing. ISMA (International Social Marketing Association), ESMA (European Social Marketing Association), and AASM (Australian Association of Social Marketing) (2013) defines social marketing as to seek to develop and integrate marketing concepts with other approaches to influence behavior that benefit individuals and communities for the greater social good. Abroms and Maibach (2008) concludes that most studies conducted in social marketing shows that social marketing program and campaign should involves clear focus on behavioral change, research phase, audience segmenting for target group, exchange theory, marketing mix and competitor consideration.

Lefebvre (2011) suggested eight components of social marketing: (1) consumer orientation to achieve the organization's objective, (2) emphasis on voluntary exchange of product and service between provider and program target, (3) research intended to audience analysis and segmenting strategy, (4) formative research use in product design and message and material pretesting, (5) channel distribution (communication) analysis, (6) marketing mix use - using and combining product, price, place, and promotion characteristics in designing intervention and implementation, (7) tracing process system by combining integrative and control function, and (8) management process including problem analysis, planning, implementation and feedback function. Social marketing, according to Jones and Donovan (2004) emphasizes on behavioral change with the following advantages: (1) health program is beneficial when it results in behavioral change, (2) fanatic customer emphasis, (3) ensuring that it has appropriate evaluation criteria for all activities, (4) separating social marketing with responsibility for the areas with certain different advantages such as education. This research applied social marketing process consisting of six phases : describing problem, conducting marketing research, creating marketing strategy, planning intervention; planning monitoring and evaluation, and implementation of intervention and evaluation (Centers for Disease Control and Prevention, 2014). The study aims to explore how to apply social marketing on dengue mosquito vector control and and TB case finding in Pati District, Central Java, Indonesia

\section{Method}

The research design used was cross-sectional one with sequential mixed methods. The qualitative research was conducted using case study, while quantitative research was conducted through intervention research. The research was taken place in Pati Regency, Central Java Province, Indonesia, with two villages as the sample: Kertomulyo and Tegal Harjo Villages in Trangkil Sub District. This study was conducted for 6 (six) months from June to November 2014. The research analytical unit was dengue mosquito vector control and tuberculosis case programs, and community health workers training in social marketing of dengue mosquito vector control and tuberculosis case programs. The research target includes policy makers and program executors in Regency's Health Service, Community Health Centers and Village.

The sampling techniques used were purposive and snowball sampling ones. Data collection was conducted through document analysis, field observation, in-depth interview and focus group discussion (FGD). Document study was conducted on policy, resource, and performance of dengue mosquito vector control and TB case finding programs. Field observation was conducted on community activities in dengue mosquito vector control and TB case finding programs. Meanwhile, in-depth interview and FGD were conducted with 55 participants $(\mathrm{n}=55): 40$ community leaders $(n=40)$ and 15 health workers $(n=15)$.

Intervention research was conducted on social marketing training of 30 community health workers (volunteers selected by and from the community which is in charge of of developing public health programs). The independent variable is social marketing training, while the dependent variable is knowledge of dengue mosquito vector control and TB case finding. To know the impact of the training, a written test was conducted before and after the training, the data were analyzed by paired $t$ test. Case study research analysis was conducted using content analysis, encompassing three steps: data reduction, data display, and drawing and verifying conclusion. Then, information was formulated and interpreted, interpretative analysis was conducted to reveal the best learning practice of understanding the case. 
Table 1. Dimensions of social marketing on dengue mosquito vector control and TB case finding

\begin{tabular}{|c|c|c|}
\hline No & Dimension of research & Description of social marketing \\
\hline 1 & Describing the Problem & $\begin{array}{l}\text { a. Identify health problems and community behavior that cause health problems } \\
\text { in society (main problem). } \\
\text { b. Explores the factors that influence behavior causing health problems in the } \\
\text { community. }\end{array}$ \\
\hline 2 & $\begin{array}{l}\text { Conducting a Marketing } \\
\text { Research }\end{array}$ & $\begin{array}{l}\text { a. Define segments of social marketing goals for health promotion. Differentiated } \\
\text { b. Deals that want to act/change behavior and that difficult/ not willing to act. } \\
\text { c. Determine and locate easy community goals for behavior change. } \\
\text { d. Educate people who are unhealthy. } \\
\text { e. Identify barriers to healthy behavior change. }\end{array}$ \\
\hline 3 & Marketing & $\begin{array}{l}\text { a. Seek the focus of community groups that are easy or ready to make behavioral } \\
\text { changes more effective and efficient; } \\
\text { b. Review and identify existing programs, which have not reached the target or } \\
\text { failed to meet the needs of the community; } \\
\text { c. Define the profile of the audience/target; } \\
\text { d. Submission or offer a message to the public/audience; } \\
\text { e. Determine the types of interventions appropriately using interventions aimed at } \\
\text { addressing problems by raising benefits, exploring and highlighting the } \\
\text { benefits gained by behaving healthily. }\end{array}$ \\
\hline 4 & Planning Intervention & $\begin{array}{l}\text { a. Determining the focus on health promotion goals; } \\
\text { b. Submission of interventions to objectives so as to achieve goals and create } \\
\text { desired impacts. }\end{array}$ \\
\hline 5 & $\begin{array}{l}\text { Planning Monitoring and } \\
\text { Evaluation }\end{array}$ & $\begin{array}{l}\text { a. Activities to follow the process of health promotion and assessment of health } \\
\text { promotion efforts; } \\
\text { b. Conduct data collection to determine the development and results of health } \\
\text { promotion activities; } \\
\text { c. Monitoring and evaluation is emphasized on knowledge, attitudes and changes } \\
\text { in healthy behaviors; } \\
\text { d. Measures the extent to which the invidual / community credentials are able to } \\
\text { fulfill their responsibilities for new behavioral changes. }\end{array}$ \\
\hline 6 & $\begin{array}{l}\text { The implementation of } \\
\text { intervention and evaluation }\end{array}$ & $\begin{array}{l}\text { a. Implement an intervention plan addressing health issues with social marketing } \\
\text { strategies; } \\
\text { b. Implement social marketing techniques centered on consumers in developing, } \\
\text { implementing and evaluating programs to promote changes or modification of } \\
\text { health behaviors. }\end{array}$ \\
\hline
\end{tabular}


Table 2. Operational definitions and measurement methods of study variables

\begin{tabular}{|c|c|c|c|c|c|}
\hline \multirow{2}{*}{ No } & \multirow{2}{*}{ Variable } & \multirow{2}{*}{ Operational definition } & \multirow{2}{*}{ Scale } & \multicolumn{2}{|l|}{ Measurement } \\
\hline & & & & Technique & Measurement instruments \\
\hline 1 & $\begin{array}{l}\text { Social } \\
\text { marketing } \\
\text { training on } \\
\text { dengue } \\
\text { mosquito vector } \\
\text { control and TB } \\
\text { case finding }\end{array}$ & $\begin{array}{l}\text { Providing knowledge and social } \\
\text { marketing skills as an effort to } \\
\text { disseminate ideas and ideas to change } \\
\text { community behavior on dengue mosquito } \\
\text { vector control and } \mathrm{TB} \text { case finding, } \\
\text { including: definition, describing } \\
\text { problems, conducting marketing } \\
\text { research, creating marketing strategies, } \\
\text { planning interventions, planning } \\
\text { monitoring and evaluation, } \\
\text { implementation of intervention and } \\
\text { evaluation }\end{array}$ & Dichotomous & $\begin{array}{l}\text { Focus group } \\
\text { discussion }\end{array}$ & $\begin{array}{l}\text { List of questions about the contents } \\
\text { of training, including social } \\
\text { marketing on dengue mosquito } \\
\text { vector control and TB case finding, } \\
\text { understanding social services, } \\
\text { describing problems, conducting } \\
\text { marketing research, creating } \\
\text { marketing strategies, planning } \\
\text { interventions, planning monitoring } \\
\text { and evaluation, implementing } \\
\text { interventions and evaluating }\end{array}$ \\
\hline 2 & $\begin{array}{l}\text { Knowledge of } \\
\text { dengue } \\
\text { mosquito vector } \\
\text { control }\end{array}$ & $\begin{array}{l}\text { Mastery of knowledge and understanding } \\
\text { of dengue mosquito vector control, } \\
\text { include: definition, epidemiology, } \\
\text { causes, symptoms and signs of disease, } \\
\text { transmission, first aid disease, } \\
\text { surveillance and vector control, } \\
\text { eradication of mosquito nests, the role of } \\
\text { community health workers }\end{array}$ & Continuous & Written test & $\begin{array}{l}\text { List of questions about the definition, } \\
\text { epidemiology, causes, symptoms of } \\
\text { disease, transmission, first aid } \\
\text { disease, surveillance and vector } \\
\text { control, mosquito breeding, the role } \\
\text { of community health workers }\end{array}$ \\
\hline 3 & $\begin{array}{l}\text { Knowledge of } \\
\text { the } \mathrm{TB} \text { case } \\
\text { finding program }\end{array}$ & $\begin{array}{l}\text { Mastery of knowledge and understanding } \\
\text { of the program } \\
\text { TB case finding, including: definition, } \\
\text { epidemiology, disease causes, symptoms } \\
\text { and signs of disease, diagnosis, } \\
\text { transmission, surveillance of TB cases }\end{array}$ & Continuous & Written test & $\begin{array}{l}\text { List of questions about definition, } \\
\text { epidemiology, disease causes, } \\
\text { symptoms and signs of disease, } \\
\text { disease diagnosis, disease } \\
\text { transmission, surveillance of TB } \\
\text { cases }\end{array}$ \\
\hline 4 & $\begin{array}{l}\text { Social } \\
\text { marketing skills } \\
\text { in dengue } \\
\text { mosquito vector } \\
\text { control and TB } \\
\text { case finding }\end{array}$ & $\begin{array}{l}\text { An individual's ability to disseminate } \\
\text { ideas to the community to change } \\
\text { community behavior in the dengue vector } \\
\text { mosquito control and TB case finding }\end{array}$ & Continuous & $\begin{array}{l}\text { Observation } \\
\text { and } \\
\text { document } \\
\text { review }\end{array}$ & $\begin{array}{l}\text { Checklist for observing social } \\
\text { marketing activities in dengue } \\
\text { mosquito vector control and TB case } \\
\text { finding include problem } \\
\text { identification techniques, marketing } \\
\text { research techniques, marketing } \\
\text { strategy techniques, intervention } \\
\text { techniques, monitoring and } \\
\text { evaluation techniques, intervention, } \\
\text { and evaluation techniques. }\end{array}$ \\
\hline 5 & $\begin{array}{l}\text { Dengue vector } \\
\text { control program } \\
\text { skill }\end{array}$ & $\begin{array}{l}\text { The ability of the community to } \\
\text { implement dengue mosquito vector } \\
\text { control program, including mosquito } \\
\text { breeding place eradication, larva } \\
\text { monitoring, environmental cleanliness, } \\
\text { burying, draining and closing stagnant } \\
\text { water. }\end{array}$ & Continuous & $\begin{array}{l}\text { Observation } \\
\text { and } \\
\text { document } \\
\text { review }\end{array}$ & $\begin{array}{l}\text { Checklist to observe activities } \\
\text { undertaken by the community in } \\
\text { implementing the dengue mosquito } \\
\text { vector control program, including } \\
\text { mosquito nest mitigation activities, } \\
\text { larva monitoring, maintaining } \\
\text { environmental hygiene, burying, } \\
\text { draining, and closing stagnant water. }\end{array}$ \\
\hline 6 & $\begin{array}{l}\text { TB case finding } \\
\text { program skills }\end{array}$ & $\begin{array}{l}\text { An individual's ability to implement TB } \\
\text { case finding programs which include: } \\
\text { symptom and sign recognition, } \\
\text { sputum-taking techniques, Drug Taking } \\
\text { Monitoring, and case referral }\end{array}$ & Continuous & $\begin{array}{l}\text { Observation } \\
\text { and } \\
\text { document } \\
\text { review }\end{array}$ & $\begin{array}{l}\text { Checklist to observe TB case } \\
\text { discovery program activities } \\
\text { concerning symptom and sign } \\
\text { recognition, sputum technique, Drug } \\
\text { Taking Monitoring and case referral }\end{array}$ \\
\hline
\end{tabular}




\section{Results}

\subsection{Overview of Research Location}

The area of Pati Regency comprises of $1,503.68 \mathrm{~km}^{2}$ with the population of $1,207,399$ people, and the density of 802.96 people per $\mathrm{km}^{2}$. The population growth rate is $0.73 \%$. Most of them cover the administrative area of rural as much as 401 villages $(98.76 \%$ ). Number of DHF cases was 569 (male 289 and female 280). The incidence rate is $47.2 / 100.000$ population or above the national target $(<20 / 100.000$ population), with CFR $17.4 \%$. The number of TB cases was 1,007 (604 men and 403 women). The number of new cases of smear-positive TB was 544 cases (332 men and 212 women), with cases of TB children (0-14 years) being 156. The Case Detection Rate (CDR is percentage of estimated new and relapse TB cases detected in a given year under the internationally recommended tuberculosis control strategy) amounts to $37.60 \%$, CNR (Case Notification Rate) $45.06 \%$, Cure rate $73.78 \%$, Success rate $77.32 \%$, while the number of deaths is as much as 35 people $(2.9 \%)$.

\subsection{Participants}

Table 2. The characteristics of participants

\begin{tabular}{|c|c|c|c|c|c|}
\hline \multicolumn{3}{|l|}{ Community Leaders } & \multicolumn{3}{|l|}{ Health Workers } \\
\hline Characteristics & Sum & Percentage & Characteristics & Sum & Percentage \\
\hline Sex & & & Sex & & \\
\hline Male & 15 & $37.5 \%$ & Male & 7 & $46.7 \%$ \\
\hline Female & 25 & $62.5 \%$ & Female & 8 & $53.3 \%$ \\
\hline Age & & & Age & & \\
\hline 24-39 years & 27 & $67.5 \%$ & 24-39 years & 3 & $20.0 \%$ \\
\hline $40-55$ years & 12 & $30.0 \%$ & $40-55$ years & 12 & $80.0 \%$ \\
\hline$>55$ years & 1 & $2.5 \%$ & $>55$ years & 0 & $0 \%$ \\
\hline Education & & & Education & & \\
\hline Senior High School & 29 & $72.5 \%$ & D3 (Undergraduate level) & 4 & $26.7 \%$ \\
\hline Junior High School & 9 & $22.5 \%$ & Graduate level & 11 & $73.3 \%$ \\
\hline Elementary School & 2 & $5.0 \%$ & & & \\
\hline
\end{tabular}

\subsection{The Application of Social Marketing on Dengue Mosquito Vector Control and TB Case Finding}

\subsubsection{Describing the Problem}

Result of document study shows that DHF and TB still become serious problems in Pati Regency as 29 existing Public Health Centers have been infected with DHF. IR of DHF in Pati Regency is $66.27 / 100,000$ populations in 2015 , above the national target $(<20 / 100,000$ populations). CFR of DHF in Pati Regency is $1.71 \%$ in 2015 . Meanwhile, IR of TB is $80.30 \%$ in 2015 in Pati. CNR (the number of all TB cases were treated and reported in every 100,000 of the population in a given region) is $81.0 \%$ in 2015 in Pati. Cure rate (the proportion of new smear - positive TB cases registered under DOTS - directly observed treatment short course - in a given year that successfully completed treatment) of TB patient is $73.78 \%$. SR is $77.32 \%$. Public Health Centers data show DHF and $\mathrm{TB}$ as predominant infectious diseases.

The informants say that the specific health problem the community encounters is infectious disease, including DHF and TB. An informant mentions: "the health problem felt in the Village is dengue hemorrhagic fever and TB diseases" (A/Tegalharjo/9/6/2014). The participants of FGD confirmed it as follows:

"DHF and TB are prioritized to deal with, because they are very frightening and will result in death if dealt with lately. DHF can result in Extraordinary Incidence leading to health problem. DHF and TB are related to behavior and environment health". (S/Public Health Centers of Trangkil/10/6/2014).

The community in research location determines the prioritized health problem through discussion, based on sick population number, severity, prevention and healing attempt, and public attention. An informant suggests:

"The health problem is determined through discussion in Village Health Forum - as a forum for community 
participation in developing health development at the village level. We determine the disease priority by sick population number, severity, prevention and healing, and public attention" (W/Tegalharjo/9/6/2014).

Considering the observation, many bath tubs and water reservoir are found containing DHF mosquito larva, water reservoir such as tub, jar, and etc. not closed tightly, many used goods such as can and broken bottle disposed in house yard, and people not accustomed with breeding the mosquito larva predator fish.

\subsubsection{Conducting Marketing Research}

Social marketing activity will be successful when it is carried out as targeted. The main target of social marketing includes community health workers, board of Family Wellbeing Empowerment (FEW) - a community organization that empowers women to participate in health development in Indonesia), chairman of RT (Rukun Tetangga, which is the division of villages in Indonesia as the lowest administrative division), hamlet chief, and village apparatus. A participant of FGD suggested: "targets of social marketing are health cadres, FEW administrators, RT chairperson, hamlet chief, and village apparatus" (A/Tegalharjo/9/6/2014).

These targets are an appropriate community group to adopt healthy behavior constituting community activator and role model facilitating the change of behavior. The constraints likely occurring in behavioral change are belief in shaman and some community members invited difficultly to behave healthily as a participant confirms: "some members of society are difficultly invited to change their health behavior. Such the people are small in number but affect other people" (E/Tegalharjo/9/6/2014).

Another constraint found is some community members still holding tightly on tradition inhibiting the health effort. An informant suggests as follows:

"The constraint in changing the health behavior includes those difficultly invited to change and holding tightly on the tradition inhibiting the health effort" (AHF/Tgl/06/2014). "Some people pay less attention to environment cleanliness, dispose the used goods (can and bottle) in house yard or garden, not accustomed with undertaking the action of eradicating the mosquito nests with drain, close, and utilize used good and bringing the suspected TB patient to the physician as soon as possible"(W/Tegalharjo/9/6/2014).

The attempt of dealing with this constraint is to make the people aware of it by those close to the people, reliable, and persuasive. One informant suggested that:

"To deal with those difficultly invited to change their health behavior, the cadre closest to them are required to inform or to advise them so that any says and invitation of the cadres can be heard and acceptable" (AHF/Tgl/06/2014).

Another attempt is to distinguish the community group willing to act on/to change behavior and the one not willing to. The research concludes that those changing behavior easily and readily are community leaders leading the behavioral changing program to run more effectively and efficiently. The profile of social marketing's audiences includes: having secondary education, working as farmers, merchants and factory labors, and are Moslem.

\subsubsection{Creating Marketing Strategy}

Social marketing strategy is a decision/policy making action concerning how to make the activity runs optimally, more effectively, efficiently and successfully, through identifying the community group changing their health behavior easily and readily. Considering the FGD's result, those adopting health behavior easily include community leaders (Village Chief, village government apparatus, FEW, health cadres, and religion figures). A participant of FGD confirmed that:

"In this village, those receiving explanation and following easily the invitation to behave healthily are health cadres, FEW administrators, hamlet chief, religion figures, and most women often coming to Integrated Service Posts (ie communication and technology transfer facilities in health services managed and organized by and for communities with technical support from health workers)." (I/ Public Health Centers of Trangkil/ 9/6/2014).

Social marketing strategy is conducted using the society organizations existing in the village (Integrated Service Posts meeting, FEW meeting, FEW Group (the maternal group came from 10 families), and recitation and regular social gathering meeting (arisan). A participant confirmed that: "The means of conducting social marketing activity include: Integrated Service Posts, FEW meeting, recitation and regular social gathering meeting" (T/Public Health Centers of Trangkil/9/6/2014). Through meeting, idea or message of social marketing is conveyed to society. During the meeting, the community is informed and warned to maintain environment cleanliness, eradicate the mosquito nests, be alerted to those having fever to anticipate DHF, and the suspected TB patients. 


\subsubsection{Planning Intervention}

This stage is conducted to analyze policy, organization, management, resource and context either inhibiting or facilitating the dengue mosquito vector control and TB case finding development. A participant of FGD said that:

"Health promotion program is prioritized primarily in Public Health Centers' basic program. However, it has not been implemented optimally yet. The health promotion program policy implementation at local level requires political and resource supports and the availability of health promotion officers" (I/ Public Health Centers of Trangkil/9/6/2014).

Another participant of FGD suggested that: "The organization managing public health program at village level is Village Health Forum " (A/Public Health Centers of Trangkil/9/6/ 2014). The community's health attempt taken is supported with local resources (effort, infrastructure and health fund). The informant said that: "health personnel includes village midwife and health cadres. The health infrastructure includes Public Health Centers, Village Health Post (community based health efforts established in the village in order to bring in/provide basic health services for rural communities), and Integrated Service Post" (S/Tegalharjo/9/6/2014). Another informant suggested that: "Health program funding comes from village income and expense budget and community's contribution" (P/Tegalharjo/9/6/2014).

The research concludes that the main target of behavioral change is community leaders. The appropriate intervention types are social marketing training, group education, gathering, and discussion that can be implemented through Integrated Service Posts, FEW meeting, Dasa Wisma meeting, recitation and regular social gathering meeting. Education principle is implemented through adult education. An informant said: "improving the awareness among the community leaders will be better when they are equipped with social marketing to socialize DBD mosquito vector control and TB case finding program" (J/Public Health Centers of Trangkil/9/6/2014). Furthermore, the participant of FGD suggested that:

"Local people are better informed about the cause and prevention of infectious diseases and their risk factor. Intervention through social marketing approach can deal with the constraint the rural health officer encounters in working effectively, and help implement and develop the DHF and TB DPC program" (TW/Kertomulyo/ 9/6/2014).

Another informant said that:

"The program the community needs is social marketing training in the dengue mosquito vector control and TB case finding. Meanwhile, the village government apparatus and the Village Representative Council serve to organize the health program policy at village level, and to monitor and evaluate the program" (I/ Public Health Centers of Trangkil/9/6/2014).

\subsubsection{Planning Monitoring and Evaluation}

Monitoring and evaluation are emphasized more on changing healthy behavior rather than on its effect, monitoring the improvement of knowledge and practice of clean and healthy life behavior. It was agreed that monitoring and evaluation should be focused on controlling the vector of dengue mosquitoes through mosquito nest eradication and TB case finding.

The successful mosquito of nest eradication is measured using Larva Index, and the TB case finding is measured by the amount of sputum collected and the laboratory results show the acid-fast bacilli (AFB). Data was collected through observation and report in neighborhood, Integrated Service Posts and community meetings. An informant stated:

"The activity of improving health in village is carried out by observing the cleanliness of citizens' house environment and larva index of water containers, considering the posyandu's recording, and discussing those considered as invited to change difficultly and recording those suspected as developing TB" (Wrs/Krt/06/ 2014).

Another informant added: "data was collected through visiting the citizens' house, interviewing and observing them and Posyandu activity". Still another informant explained that social marketing activity monitoring and evaluation is conducted by identifying the change of health behavior. An informant suggested: "We monitor the community movement in eradicating mosquito nests, and those developing DHF and TB symptoms" $(\mathrm{Ps} / \mathrm{Krt} / 06 / 2014)$.

\subsubsection{The Implementation of Intervention and Evaluation}

In this research, the implementation of intervention is conducted through social marketing training in DHF and TB DPC program, aiming to improve the knowledge and skill of identifying, determining priority, and solving health 
problem, identifying potential local resource, detecting disease earlier, monitoring and evaluating the dengue mosquito vector control and TB case finding, and conducting social marketing for behavioral change. The target of training includes health cadres. Thirty participants are involved in the training: 4 community leaders/village, 6 FEW administrators/village, and 5 health cadres/village.

Table 3. Characteristics of Social Marketing Training Participants

\begin{tabular}{lll}
\hline Characteristics & Sum & Percentage \\
\hline Sex & 11 & $37.0 \%$ \\
Males & 19 & $63.0 \%$ \\
Females & 8 & $30.0 \%$ \\
Age category (year) & 22 & $70.0 \%$ \\
$24-39$ & - & - \\
$40-55$ & 3 & $10.0 \%$ \\
Above 55 & 19 & $63.3 \%$ \\
Education Level & 7 & $23.3 \%$ \\
Graduated from University & 1 & $3.4 \%$ \\
Graduated from Senior High School & & \\
Graduated from Junior High School & & \\
Graduated from Elementary School & &
\end{tabular}

Material of training includes dengue mosquito vector control and TB case finding programs and social marketing. Instrument of training used a flipchart about dengue mosquito vector control and tuberculosis case programs - a two-sided flipchart with one side designed to serve as a social marketing material for clients and the other side acting as a work aid for the guidance of healthy behavior change. The training method employed was adult learning method through discussion, debriefing, FGD training, and experience exchange, while the trainer serves as facilitator. To know the impact of cadre training intervention implementation on cadre training improvement on social marketing of vector control of dengue mosquito and TB case finding, written test before and after training by using questionnaire instrument, then data were analyzed by paired $t$ test.

a. The effect of training on the improvement of knowledge on the dengue mosquito vector control

The effect of cadre training shows the cadres' improved knowledge on the dengue mosquito vector control. Result of Wilcoxon's statistic test on the difference of training participants' knowledge before and after training is presented in Table 4.

Table 4. Wilcoxon test on the difference of knowledge score on the dengue mosquito vector control before and after training

\begin{tabular}{lllllll}
\hline Group & $\mathrm{n}$ & Mean & Median & SD & Wilcoxon Z & $\mathrm{p}$ \\
\hline Before & 30 & 12.37 & 16.00 & 1.60 & -3.53 & 0.001 \\
After & 30 & 13.60 & 18.00 & & & \\
\hline
\end{tabular}

Considering the result of statistic test, it can be found $\mathrm{p}$ value $(0.001)<<\alpha(0.005)$, meaning that there is a significant difference of knowledge on the dengue mosquito vector control before and after training. The training participants' average knowledge on the dengue mosquito vector control before training is 12.37 , while that after training is 13.60. After training there was an increase in the cadre's knowledge about dengue mosquito vector control (increased by 1.23 points). Increasing the value of this knowledge is very meaningful for efforts to dengue mosquito vector control.

b. The effect of training on the improvement of knowledge on the TB case finding programs 
The effect of cadre training shows the cadres' improved knowledge on the TB case finding programs. The result of Wilcoxon's statistic test on the difference of training participants' knowledge before and after training is presented in Table 5.

Table 5. Wilcoxon test on the difference of knowledge score on the TB case finding programs before and after training

\begin{tabular}{lllllll}
\hline Group & $\mathrm{n}$ & Mean & Median & SD & Wilcoxon Z & $\mathrm{p}$ \\
\hline Before & 30 & 15.60 & 16.00 & 2.00 & 3.74 & 0.001 \\
After & 30 & 17.37 & 18.00 & & & \\
\hline
\end{tabular}

Considering the result of statistic test, it can be found $p$ value $(0.001)<\alpha(0.005)$, meaning that there is a significant difference of knowledge on the TB case finding programs before and after training. The training participants' average knowledge on the TB case finding programs before training is 15.60 . Meanwhile that after training is 17.37. After training there was an increase in the value of cadre knowledge about TB case finding (increased by 1.77 points). Increasing the value of this knowledge is very meaningful for the efforts of TB case finding in the community.

c. The effect of training on the improvement of social marketing knowledge on the dengue mosquito vector control and TB case finding

The effect of cadre training shows the cadres' improved knowledge on social marketing in dengue mosquito vector control and tuberculosis case programs. The result of Wilcoxon's statistic test on the difference of training participants' social marketing knowledge before and after training is presented in Table 6 .

Table 6. Wilcoxon test on the difference of social marketing knowledge on dengue mosquito vector control and TB case finding programs before and after training

\begin{tabular}{lllllll}
\hline Group & $\mathrm{n}$ & Mean & Median & SD & Wilcoxon Z & $\mathrm{p}$ \\
\hline Before & 30 & 13.93 & 16.00 & 2.39 & -3.82 & 0.001 \\
After & 30 & 15.90 & 18.00 & & & \\
\hline
\end{tabular}

Considering the result of statistic test, it can be found $p$ value $(0.001)<\alpha(0.005)$; Ho is not supported, meaning that there is a difference of participants' knowledge on the social marketing of dengue mosquito vector control and TB case finding programs before and after training. The participants' average knowledge on social marketing before training is 13.93 , while that after training is 15.90 . After the training there was an increase in the value of cadre knowledge about social marketing program of dengue mosquito vector control and TB case finding programs (increased 1.97 points). This increase in the value of knowledge is highly meaningful in the social marketing efforts of dengue mosquito vector control and TB case finding programs.

d. The effect of training on the improvement of social marketing skill in dengue mosquito vector control and TB case finding programs

The effect of cadre training shows the cadres' improved skill of implementing the social marketing in dengue mosquito vector control and TB case finding programs within society, as shown with result of observation on cadre activities indicating the cadres approaching and educating the community and searching for suspected TB patient, taking sputum and conducting the action of eradicating dengue mosquito vector control through drain, close, and utilize used goods movement, and skilled in mosquito larva monitoring.

\section{Discussion}

Social marketing studies are dominated by qualitative method, despite more prominent quantitative and mixed methods. Public health becomes main topic of social marketing studies contributing $71.4 \%$ of topic. Most social marketing discourses focus on individual behavioral change (Truong, 2014). USAID has funded social marketing in family planning and public health areas in developing countries (Lefebvre, 2011). USAID has funded social marketing studies and program for 40 years in more than 30 countries for infant mortality, HIV/AIDS, nutrition and environment protection (Smith, 2014). 
Bennadi, Kashinath and Bharateesh. (2014) argues that social marketing is a behavioral change approach evidently effective in health promotion and disease prevention study area. Considering behavioral and communication theory, it can be seen that social marketing can be diverted to other topic and domain. Marketing principle and practice offer new way of seeing old and new problems to trigger creativity (Budiharseno, 2017). Evans (2006) summarizes six basic elements of the social marketing procedure. Those are developing plan and strategy using behavioral theory, choosing communication channel and material based on behavioral change needed and target audience's knowledge, developing and pretesting the material, conducting communication or campaigning program, assessing the effectiveness of audiences' elaboration and awareness, reaction to the message and behavioral outcome, accomplishing the material to the future communication, and feedback. Pechmann and Catlin (2016) showed that social marketing can exert a significant and measurable effect on cognition, emotion and behavior. French (2011), said that successful social marketing program starts with clear realistic objective and measurable behavior goal. Behavioral theory is used to inform and to guide all social marketing interventions.

The framework of marketing and social marketing highlights the important role of "value" in behavior or behavioral change context. People are motivated to act on either buying product or service or adopting behavior, as doing so provides or helps achieve something they value (Wahyuni \& Ginting, 2017). Most people pay much attention to the benefit and they care much about the information on primary benefit communicated in meaningful ways (e.g. through storytelling, emotional expression, and interesting message) (Nowak, Gellin, MacDonald, \& Butler, 2015; Nugroho, Bakar, \& Ali, 2017).

Result of current research shows that social marketing training improves knowledge and skill of health cadres. Biroscak, Lefebvre, Schneider, Marshall and McDermott (2014) confirms that the public health officer training's objective is to improve their performance capacity. When the performance capacity is defined, training program should be directed to improve the competency. The challenge of public health training and other social effort is how they can expand the need for social marketing competency development identified among training participants. Li, Cao, Lin, Li and Wang (2009) suggests that training is very important to the successful healthy behavior change. Study of Lacko, Lacko, Malcolm, West, Rose and London (2013) concluded that the short-term positive consequence of social marketing campaign is that social contact can be used for anti-stigma program to reduce stigma.

Sweat, Denison, Kennedy, Tedrow, and O'Reilly (2012) meta-analysis showed a statistically positive significant effect on the increased condom use, and all individual studies show positive trend. The evidence shows that health communication campaign combined with other strategy (e.g., community activity) affects more the improvement of healthy behavior compared with the use of single strategy (e.g., poster campaign). Robinson et al. (2014) concluded that health communication campaign combining mass media and other communication channel through distributing free health product effectively improves healthy behavior. Message should be confirmed through repeating elaboration, expanding campaign message coverage and target audience, and exerting short-term effect on behavioral change. Furthermore, the improvement of corresponding health product's availability, accessibility, and affordability can improve health behavior adoption and maintenance, thereby reducing morbidity and mortality.

Van Rosseem and Meekers (2007) concluded that social marketing of condom advertisement and radio and television programs about family planning and HIV/AIDS has successfully reached most Zambians. Result of studies shows that the campaign for communicating reproductive health should attempt to improve its effect on women, by focusing on specific constraint preventing the women from using condom. Furthermore, other studies show that specific message content of radio and television campaign has high retention and strong effect on condom use.

Horn, Jarrett, Anesetti-Rothermel, Tompkins and Dino (2014) applied social marketing combined with innovation diffusion and social cognitive theory as the evidence-based model of socializing the smoking habit ceasing intervention among adolescents in West Virginia called not-on-tobacco (N-O-T). This model focused primarily on focusing the responsibility and allowing for local locus control (local area coordinator) aiming to fulfill more the need and challenge of N-O-T facilitator and adolescents at local level. Tan et al. (2010) concluded that public health intervention is directed to the community participation potentially involving older adults likely not responding to the improvement of their health.

Boonchutima, Kachentawa, Limpavithayakul, Prachansri (2017) study reported over a three-year period, a positive trend was revealed in relation to the media's contribution in educating and reminding the Thai population of dengue, without uniformity or powerful campaigns. Based on the results of this study, it is concluded that despite the measures undertaken to prevent dengue fever, media exposure is insufficient. An interdisciplinary 
approach involving the community participation, media, and government is needed to address the threat of dengue in Thailand. Furthermore, Swaddiwudhipong et al. (1992) study reports on the impact of health education efforts on community-based dengue vector control programs in Mae Sot District, Tak Province, northern Thailand. Public health education on DHF and larval control through mass media, lectures and discussions reduced the Aedes Breteau index from 241 to 126 . House-to-house visits by trained health workers were added to the health education campaigns, lowering the Aedes larvae index. Further research case studies Parks (2004) concluded that there is strong evidence that social mobilization and communication are essential to sustainable dengue prevention and control. Therefore, a new paradigm for sustainable dengue prevention and control is emerging and with it, we are learning more effective ways to engage the general public and other key stakeholders in the task of controlling this disease

Luna et al. (2004) conducted a study on an integrated social mobilization and communications approach in the City of Bucaramanga, northeastern Colombia. The program is focused on one day of the week (ie Thursday) - as Dengue Prevention Day, where citizens were to seek and clean up the Aedes aegypti mosquito place, communication and educational actions were used to mobilize and motivate the people. At the same time, innovative printed materials were designed and disseminated resulting in massive mobilization of students, housekeepers and other publics. The programme also produced features materials and methodology of interpersonal communication, and mobile dengue exhibits with interactive educational games, resulting in partnerships with the private sector and community groups. After 8 months of evaluation, it was found that $94 \%$ of the teachers and $96 \%$ of the students knew about the calendar and $88 \%$ of the teachers and $77 \%$ of the students used it. The impact on households of messages broadcast on radio from 2002-2003 was evaluated. 27 percent of people admitted Thursday as Dengue Prevention Day as well as knowing and practicing specific measures to locate and control Ae aegypti, To monitor behavioural impact among housewives and the rest of the population, the House Index was measured every three months. Results showed the index decreased from 18\% in 1998 to 5\% in 2003.

Research Hairi et al. (2003) concluded that public knowledge of Aedes' control was good, of the 200 respondents, $82.0 \%$ cited that their main source of information on dengue was from television/radio. The mass media is an important means of delivering health messages to the general public even among the rural population. The respondents' attitude was found to be good and most of them were supportive of Aedes control measures. There is a significant association found between knowledge of dengue and attitude towards Aedes control $(\mathrm{p}=0.047)$. But good knowledge does not necessarily lead to good practice. Practice of dengue control was lacking due to certain deeply ingrained cultural practices.

Chinnakali et al. (2012) conducted a study of 215 individuals. Majority of the respondents (96.3\%) had heard about dengue. The important sources of information were television (54.9\%) and newspaper/ magazines (51.7\%). Around $89 \%$ of the study participants considered dengue as "serious problem." Nearly $86 \%$ participants were aware of the spread of dengue by mosquitoes while $73 \%$ were aware of one of the correct breeding sites of Aedes mosquito. The awareness regarding dengue and mosquito control measures was satisfactory to an extent. Programs should focus that this knowledge gets translated into practice. Furthermore, Wong and AbuBakar's study (2013) concludes that behavioural change towards attaining sustainability in dengue preventive practices may be enhanced by fostering comprehensive knowledge of dengue and a change in health beliefs.

A study from Shuaib, Todd, Campbell-Stennett, Ehiri and Jolly (2010) concluded that a good knowledge about dengue fever among Westmoreland residents did not translate to the application of preventive measures. Health promoters and practitioners need to identify and facilitate removal of barriers to behavior change related to dengue control among the population. Future campaigns should focus on educating and encouraging individuals and families to adopt such simple and inexpensive precautions, such as, use of insecticide treated bed nets and screening of homes. Furthermore, research Pérez-Guerra, Zielinski-Gutierrez, Vargas-Torres and Clark (2009) concluded that suggested strategies to motivate citizen action included working with government agencies to address structural issues that increase mosquito populations, improve access to information on garbage collection and drainage through telephone hotlines, improve publications and information about dengue through media mass campaigns, and educating healthprofessionals.

Shargie, Mørkve and Lindtjørn (2006) conducted a 4 days training program for public health workers on case detection, diagnostic procedures, outreach coordination, handling of sputum specimens, interview techniques, and record-keeping. Meanwhile, community health promoters held discussions with community leaders to set an appropriate monthly date for a diagnostic outreach clinic. Every month, before the outreach day, community health promoters went around the village for 3-4 consecutive days visiting homes, distributing TB tuberculosis leaflets, 
and discussing possible TB symptoms with individuals, households and community groups. They also promoted messages about TB in schools and popular meetings in the intervention area. They encourage symptomatic TB suspects to visit outreach teams or nearby health facilities if desired. These interventions are effective in enhancing the discovery of smear-positive TB cases.

A research results from Lo"nnroth, Aung, Maung, Kluge, and Uplekar (2007) concluded that TB program services are better through franchise clinics. This study suggests that social franchising of TB care can contribute positively to public health, including equity in access to quality care and financial protection for the poor. The findings in this study indicate that patients mainly followed their habitual health-seeking behaviour, and first learnt about 'DOTS' and free treatment for TB when they had come to the GP. Further research Jaramillo (2001) reported an evaluation of the impact of mass media health education campaigns for TB control on case finding in Cali, Colombia. The Impact assessment shows that the campaign resulted an increase of $64 \%$ in the number of direct smears processed by the laboratories and an increase of $52 \%$ in the number of new cases of positive pulmonary TB, compared with the previous period.

Limitations of the research - The social marketing application in this study does not monitor and evaluate the results of behavioral changes at the individual, family and community level, so it cannot assess the impact of behavioral changes on the DBD mosquito vector control program and TB case finding. However it has been agreed that monitoring and evaluation is focused on controlling the vector of dengue mosquitoes through mosquito breeding place eradication and TB case finding. The purposive sampling technique can limit the generalizability of the study results (Yin, 2003). This study was conducted in rural areas, and it cannot be generalized in all areas.

\section{Conclusion}

It was concluded that social marketing enhances knowledge and skills and can be used for behavioral change in dengue mosquito vector control and TB case finding. This study has at least four important implications. First, social marketing can change behavior in prevention and control of dengue and TB case finding. Second, passive case finding TB is likely to be an insufficient strategy to achieve CDR targets, for which case it needs to be supported by the active case finding TB with a social marketing approach. Third, providing knowledge and information on vector control of dengue mosquitoes as well as early symptoms and diagnostic TB procedures can improve stagnant water drainage, closure, and good re-use movement, and larva monitoring, and improvement in TB case finding. Fourth, the use of flipcharts on dengue mosquito vector control and TB case finding programs can help CHWs to improve community knowledge, awareness and healthy behavior change.

\section{Acknowledgements}

The authors would like to thank to Chairperson of Research and Service-to-Community Institution of Sebelas Maret University for funding this research in University Superior Research scheme. They also express their gratitude to Local Government of Pati Regency, Central Java, for permitting and facilitating this research.

\section{Competing Interests Statement}

The authors declare that there are no competing or potential conflicts of interest.

\section{References}

Abroms, L. C., \& Maibach, E. W. (2008). The Effectiveness of Mass Communication to Change Public Behavior. Annual Review of Public Health, 29, 219-234. https://doi.org/10.1146/annurev.publhealth.29.020907.090824

Bennadi, D., Kashinath, K. R., \& Bharateesh, J. V. (2014). Social Marketing-Its Initial Concepts. Indian Journal of Research in Pharmacy and Biotechnology, 2(4), 1257-1262.

Biroscak, B. J., Lefebvre, R. C., Schneider, T., Marshall, R. J., \& McDermott, R. J. (2014). Assessment of social marketing education, training, and application in public health settings. International Review on Public and Nonprofit Marketing, 11, 145-160. https://doi.org/10.1007/s12208-013-0111-y.

Boonchutima, S., Kachentawa, K., Limpavithayakul, M., \& Prachansri, A. (2017). Longitudinal study of Thai people media exposure, knowledge, and behavior on dengue fever prevention and control. Journal of Infection and Public Health, 10, 836-841. https://doi.org/10.1016/j.jiph.2017.01.016

Budiharseno, R. S. (2017). Factors Affecting Online Buying Behavior on G-Market Site Among International Students in Busan: A Qualitative Research. Arthatama: Journal of Business Management and Accounting, 1(1), 1-5. Retrieved from http://www.arthatama-jbma.com/index.php/arthatama-jbma/article/view/9/2

Centers for Disease Control and Prevention. (2014). CDCynergy Lite: Social Marketing Made Simple A guide for creating effective social marketing plans. Atlanta, GA: Centers for Disease Control and Prevention. 
Retrieved from https://www.cdc.gov/ healthcommunication/ cdcynergylite.

Chinnakali, P., Gurnani, N., Upadhyay, R. P., Parmar, K., Suri, T. M., \& Yadav, K. (2012). High Level of Awareness but Poor Practices Regarding Dengue Fever Control: A Cross-sectional Study from North India. North American Journal of Medical Sciences, 4(6), 278-282. https://doi.org/10.4103/1947-2714.97210

Evans, W. D. (2006). How social marketing works in health care. BMJ, 32(20), 1207-10. https://doi.org/10.1136/bmj.332.7551.1207-a

French, J. (2011). Why nudging is not enough. Social Marketing Journal, 1(2), 154-162. https://doi.org/10.1108/20426761111141896

Horn, K., Jarrett, T., Anesetti-Rothermel, A., Tompkins, N. O. H., \& Dino, G. (2014). Developing a dissemination model to improve intervention reach among West Virginia youth smokers. Public Health Education and Promotion, 2(101), 1-13. https://doi.org/10.3389/fpubh.2014.00101

International Social Marketing Association, European Social Marketing Association, \& Australian Association of Social Marketing. (2013). Consensus definition of social marketing. Retrieved from http://www.isocialmarketing.org/assets/social_marketing_definition.pdf

Jaramillo, E. (2001). The impact of media-based health education on tuberculosis diagnosis in Cali, Colombia. Health Policy and Planning, 16, 68-73. https://doi.org/10.1093/heapol/16.1.68

Jones, S, C., \& Donovan, R. J. (2004). Does theory inform practice in health promotion in Australia? Health Education Research, 19(1), 1-14. https://doi.org/10.1093/her/cyg002

Lacko, S.E., Malcolm, E., West, K., Rose, D., \& London, J. (2013). Influence of Time to Change's social marketing interventions on stigma in England 2009-2011. The British Journal of Psychiatry, 202, s77-s88. https://doi.org/10.1192/ bjp.bp.113.126672. 202.

Lefebvre, R.C. (2011). An integrative model for social marketing. Journal of Social Marketing, 1(1), 54-72. https://doi.org/10.1108/20426761111104437

Li, Y., Cao, J., Lin, H., Li, D., \& Wang, Y. (2009). Community health needs assessment with precede-proceed model: a mixed methods study. BMC Health Services Research, 91(81), 1-14. https://doi.org/10.1186/1472-6963-9-181

Lo"nnroth, K., Aung, T., Maung, W., Kluge, H., \& Uplekar, M. (2007). Social franchising of TB care through private GPs in Myanmar: an assessment of treatment results, access, equity and financial protection. Health Policy and Planning, 22, 156-66. https://doi.org/10.1093/heapol/czm007

Luna, J.E., Chain, I., Hernandez, J., Clark, G.G., Bueno, A., Escalante, R., Angarita, S., \& Martinez, A. (2004). Social Mobilization Using Strategies of Education and Communication to Prevent Dengue Fever in Bucaramanga, Colombia. World Health Organization. Dengue Bulletin, 28(Suppl).

Ministry of Health Republic of Indonesia. (2010). Center of Data for Epidemiological Surveillance. Epidemiology Window Bulletin Key Topic of Dengue Hemorrhagic Fever (Vol. 2). August. Jakarta: Ministry of Health Republic of Indonesia.

Ministry of Health Republic of Indonesia. (2016). General Secretariat. Indonesia Health Profile Year 2015. Jakarta: Ministry of Health Republic of Indonesia.

Nowak, G. J., Gellin, B. G., MacDonald, N. E., \& Butler, R. (2015). Addressing vaccine hesitancy: The potential value of commercial and social marketing principles and practices. Vaccine, 33, 4204-4211. https://doi.org/10.1016/j.vaccine.2015.04.039

Nugroho, A. H., Bakar, A., \& Ali, A. (2017). Analysis of Technology Acceptance Model: Case Study of Traveloka. Arthatama: Journal of Business Management and Accounting, 1(1).

Pechmann, C., \& Catlin, J. R. (2016). The effects of advertising and other marketing communications on health-related consumer behaviors. Current Opinion in Psychology, 10, 44-49. https://doi.org/10.1016/j.copsyc.2015.12.008

Pérez-Guerra, C. L., Zielinski-Gutierrez, E., Vargas-Torres, D., \& Clark, G. G. (2009). Community beliefs and practices about dengue in Puerto Rico. Revista Panamericana de Salud Pública, 25(3), 218-226. https://doi.org/10.1590/S1020-49892009000300005

Robinson, M. N., Tansil, K. A., Elder, R. W., Soler, R. E., Labre, M. P., Mercer, S. L., ... \& Sokler, L. A. (2014). Mass media health communication campaigns combined with health-related product distribution: A 
community guide systematic review. American Journal of Preventive Medicine, 47(3), 360-371. https://doi.org/10.1016/j.amepre.2014.05.034

Shargie, E. B., Mørkve, O., \& Lindtjørn, B. (2006). Tuberculosis case-finding through a village outreach programme in a rural setting in southern Ethiopia: community randomized trial. Bulletin of the World Health Organization, 84(2), 112-119. https://doi.org/10.2471/BLT.05.024489

Shuaib, F., Todd, D., Campbell-Stennett, D., Ehiri, J., \& Jolly, P. E. (2010). Knowledge, attitudes and practices regarding dengue infection in Westmoreland, Jamaica. The West Indian Medical Journal, 59(2), 139-146. Retrieved from https://www.ncbi.nlm.nih.gov/pmc/articles/PMC2996104/

Smith, B. (2014). If safety were all we thought of, who would ever fall in love? Social marketing: A look back. Social Marketing Quarterly, 20(1), 11-14. https://doi.org/10.1177/1524500413519543

Swaddiwudhipong, W., Chaovakiratipong, C., Nguntra, P., Koonchote, S., Khumklam, P., \& Lerdlukanavonge, P. (1992). Effect of health education on community participation in control of dengue hemorrhagic fever in an urban area of Thailand. Southeast Asian Journal of Tropical Medicine and Public Health, 23, 200-206.

Sweat, M. D., Denison, J., Kennedy, C., Tedrow, V., \& O'Reilly, K. (2012). Effects of condom social marketing on condom use in developing countries: a systematic review and meta-analysis, 1990-2010. Bulletin of the World Health Organization, 90(8), 613-622A. https://doi.org/10.2471/BLT.11.094268

Tan, E. J., Tanner, E. K., Seeman, T. E., Xue, Q. L., Rebok, G. W., Frick, K. D., ... \& Whitfield, K. E. (2010). Marketing public health through older adult volunteering: experience corps as a social marketing intervention. American Journal of Public Health, 100(4), 727-734. https://doi.org/10.2105/AJPH.2009.169151

Truong, V. D. (2014). Social Marketing: A Systematic Review of Research 1998-2012. Social Marketing Quarterly, 20(1), 15-34. https://doi.org/10.1177/1524500413517666

Van Rossem, R. V., \& Meekers, D. (2007). The reach and impact of social marketing and reproductive health communication campaigns in Zambia. BMC Public Health, 7(352), 1-12. https://doi.org/10.1186/1471-2458-7-352

Wahyuni, S., \& Ginting, M. (2017). The Impact of Product Quality, Price, and Distribution on Purchasing Decision on the Astra Motor Products in Jakarta. Arthatama: Journal of Business Management and Accounting, 1(1), 18.

Wong, L. P., \& AbuBakar, S. (2013). Health beliefs and practices related to dengue fever: a focus group study. PLoS neglected tropical diseases, 7(7), e2310. https://doi:10.1371/journal.pntd. 0002310

World Health Organization. (2016). WHO report 2015: Global tuberculosis control. Geneva: World Health Organization.

Yin, R. K. (2003). Case Study Research: Design and Methods. London: Sage Publication.

\section{Copyrights}

Copyright for this article is retained by the author(s), with first publication rights granted to the journal.

This is an open-access article distributed under the terms and conditions of the Creative Commons Attribution license (http://creativecommons.org/licenses/by/4.0/). 